\title{
Mindfulness Practices And Learning Economics
}

\author{
David R. Borker, Manhattanville College, USA
}

\begin{abstract}
There is a growing interest among educators in teaching and learning practices based on mindfulness, a concept derived from eastern meditative traditions. This paper describes how mindfulness practices and concepts can be used to enhance the student's learning experience in beginning economics courses. Specific areas with a high potential for learning enhancement are identified: grasping abstract economic concepts, seeing beyond obvious economic consequences, and finding one's own ethical framework in economic analysis. Current research linking mindfulness practices to student development in these areas is examined and practical methods are offered to integrate mindfulness into the economics classroom.
\end{abstract}

Keywords: Mindfulness; Economics and Business Education; Meditation; Contemplative Studies

\section{INTRODUCTION}

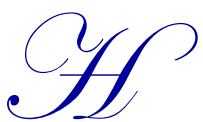

igher education is perceived as challenged in many areas. On the one hand, assessment of student knowledge gained from coursework using standardized testing indicates in the view of many that student command of the basic subject matter, particularly in complex or technical disciplines, is in on a long-term decline. A recent study of national assessment testing in economics conducted between 1968 and the present indicates that for a variety of different kinds of institutions, and at varying levels of study, there has been a consistent decline in the level of performance (Green, Stone, DeVon, \& Zegeye, 2013). This is true in spite of the fact that textbook materials and other instructional delivery systems are far more efficient and convenient than ever before. On the other hand, some see academe as highly efficient at disseminating information but unable to empower students to develop a sense of purpose and a critical view of what they are learning, based on selfawareness and recognition of what is of value in their lives. If, as is claimed, students forget $90 \%$ of what they learn soon after completing their courses, it is all the more important that they take with them long-term habits of thoughtfulness, self-awareness and a spiritual dimension for their futures (Smilovitz, 1996). Clearly, there is good reason to continue the search for creative and innovative approaches to teaching and learning in all academic disciplines.

The purpose of this paper is to describe how mindfulness practices, derived from the eastern tradition of meditation and contemplation, can contribute to student learning and growth and to apply these concepts to the educational challenges confronted in basic microeconomics or macroeconomics classes. The paper expands ideas presented in a previous publication on mindfulness practices in accounting and business courses (Borker, 2013). Economics, like accounting, is a technical and conceptually demanding subject and, unfortunately, both are not always remembered fondly by former students. Both subjects make technical demands on students and both require, but do not always deliver, a deep understanding of ethical and social issues. In addition to practices directly associated with mindfulness meditation; i.e., mindful breathing, noble silence, deep listening, practices are expanded to include a focus on contemplation and contemplative activities as these are the basis for extending the openness of mindful meditation to outside objects, such as, ideas, concepts, and issues (Hanh T. N., 2012b).

Mindfulness meditation and contemplative practices can make an important contribution to learning and personal growth by calming and opening the mind to create a condition and, hopefully, a habit of awareness and focus. Contemplation facilitates the student's personal involvement in the object contemplated and leads to personal, experiential involvement in the concepts and meaning of the subject matter. Recognition of the value of 
this approach can be seen in the proliferation of mindfulness and contemplative studies organizations focusing on K12 and higher education. These include The Center for Contemplative Mind for Society, the Mind and Life Institute, the Garrison Institute, and many others. Contemplative studies is not simply an independent subject matter offering, but is becoming a major component of the academic courses in a variety of disciplines, including the humanities, social and natural sciences and, in particular, economics. This trend is reflected in numerous colleges and universities, including undergraduate programs at Amherst College, Brown University, Emory University, Naropa University, N.Y.U, Rice University, Smith College, University of Michigan, University of the Redlands, and graduate and professional programs, such as Columbia Teachers College, University of Massachusetts Medical School and Harvard Law School. It is also reflected by numerous mindfulness and completive studies research programs, such as in U.C.L.A., Stanford, and Harvard. Although there is much diversity, both conceptually and in practice, among these organizations, they all appear to share a common appreciation of the value of mindfulness meditation and awareness of the present moment.

The remainder of this paper presents a review of the relevant literature and describes the basic mindfulness practices that can enrich and transform learning in higher education. These practices are then applied to three selected problematic learning areas in introductory economics. Finally, the value of mindfulness practices is summarized by describing the characteristics of a mindful economics classroom. In the conclusion, directions are indicated for further research.

\section{LITERATURE REVIEW}

The term mindfulness has been cited in the social science and education literature for more than three decades. Much of this literature, however, has had little to do with the direct experience of mindfulness through Eastern meditation and contemplative activity. Such literature creates its own construct of mindfulness and the mindful classroom consisting of a collection of already existing useful western cognitive strategies, including exploring possibilities and perspectives, introducing ambiguity, and focusing on the student taking an active, rather than passive, role in his/her learning (Langer, Blank \& Chanowitz, 1978; Ritchhart \& Perkins, 2000; Langer \& Moldoveanu, 2000).

The potential of mindfulness in higher education as a meditation based process for calming the mind/body, and contemplating and experiencing personal insight, represents a parallel research track that began more recently. Although his research, beginning in 1982, deals primarily with mindfulness applications for the medical science, Jon Kabat-Zinn has inspired many educators to see the value of mindfulness meditation and related practices in higher education. He has recently co-edited a collection of articles for Contemporary Buddhism, including applications in higher education and other areas (Kabat-Zinn, 1982; Williams \& Kabat-Zinn, 2011). There is significant general research on the use of mindfulness and contemplative studies in higher education (Barbezat \& Pingree, 2012; Mahani, 2012; Davidson et al., 2012; Newmark, Krahnke \& Seaton, 2012; Bush, 2011; Palmer, 2010; Zonjonc, 2006; Awbrey S., 2006). Research on mindfulness approaches in higher education cover a broad range of academic areas of study, including liberal arts, ethics, law, and medicine. (Please, see references in the website of the Center for Contemplative Mind in Society, recommended reading list). (The Center for Contemplative Mind in Society, 2013).

Literature on the use of mindfulness meditation practices in accounting and business is limited to a few articles (Borker, 2013; Chang, Davis, \& Kaufmann, 2011). In addition to pedagogical research, there is also considerable research on the application of mindfulness and contemplative methods in business organization and practices (Dollman \& Bond, 2011; Rudy \& Schweitzer, 2011; Borden \& Shekhawat, 2010). Michael Carroll, with his strong grounding in eastern meditation traditions, makes a valuable contribution to our understanding of the application of mindfulness meditation and contemplative methods to leadership in business (Carroll, 2011).

Research on mindfulness meditation and contemplative activities in the teaching of economics is promising, but sparse. Barbezat offers examples from teaching in an article on contemplative pedagogy and also demonstrates how he would introduce the topic of demand using contemplative methods in a webinar (Barbezat \& Pingree, 2012; Barbezat, 2013). Mindfulness and Buddhist ideas can, of course, be found in non-pedagogical economic research and throughout the writings of the great social economist Amartya Sen. (Ash, 2008; Alexandrin, 1981; Sen, 2013). These, however, focus on a specific type of economic theory and not on teaching economics. 


\section{MINDFULNESS PRACTICES}

The foundation of all eastern-based practices is mindfulness meditation, which forms the central basis of spiritual practice in Buddhism. From meditation, the individual experiences directly being in the present moment where the mind and body are calm and capable of clear focus within. Contemplation is the externalization or extension of meditation practice beyond meditation to the observation of objects in the world. This constitutes contemplation. The specific processes of meditation and contemplation, along with related practices, are described below.

\section{Mindfulness Meditation}

The process of mindfulness meditation has been passed down in oral tradition since the time of the Buddha. It is explained in detail in the Sutra on the Full Awareness of Breathing (Hanh T. N., 2012a). The process can be simplified to a simple set of instructions:

- $\quad$ Sit comfortably and silently with good posture in a quiet space

- $\quad$ Focus your attention on your own in- and outbreaths

- $\quad$ Observe the natural process of your body as if your body is breathing you

- $\quad$ Breathe naturally from the belly, as a baby does

- $\quad$ Feel how your mind and body are calming

- $\quad$ Experience being totally in the present moment.

Mindful breathing involves focusing attention on one's own breathing, as if the mind were a witness to this natural process of the body. By being fully aware and, at the same time, not forcing the breath, a person naturally breathes more slowly and diaphragmatically. The process is calming and supports a state of mindfulness. Mindful breathing puts the mind and body in a state of calm presence in the moment with openness to perceptions, ideas or concepts without mental obstructions or distractions. If a negative feeling arises during the meditation, such as fear, anxiety, anger, sadness or despair, the practitioner must not try to negate or destroy the feeling, but rather acknowledge it, embrace it and reassure it, as a mother would her child.

Mindful breathing can be done at any time outside of meditation and students are encouraged to engage in it as often as they wish as a way to be fully present in their lives. It is valuable as a tool for resting and can be done as a form of sitting relaxation or meditation in place of napping at strategic points in the day. If the student becomes caught up in distracting thoughts or feelings, such relaxation provides an opportunity to acknowledge these and accept them as they are so that they can gradually be transformed into something positive. Tich Nhat Hanh writes,

Our breathing is a stable solid ground that we can take refuge in. Regardless of our internal weather - our thoughts, emotions and perceptions - our breathing is always with us like a faithful friend. Whenever we feel carried away or sunken in a deep emotion, or scattered in worries and projects, we return to our breathing to collect and anchor our mind (Hanh T. N., 2012b).

Mindfulness meditation is often initiated and terminated by three rings from a bowel-shaped mediation bell (see http://www.mindfulnessbell.org/thay.php). After each ring of the bell, time is left for at least three mindful breaths to be completed. The use of the mindfulness bell can also be used as a means of initiating and ending class sessions or meetings outside of formal meditation. In these contexts, the series of rings and the mindful breathing that follows can function as a trigger to the mind to be calm, open and ready for sustained mindful concentration. The use of the mindfulness bell at the beginning of class allows the student a moment of transition from the activities and preoccupations of each student prior to arriving at class to a common state of calm, focus and openness. Use of the bell at the end of class serves as a means of refreshing the students prior to their return to the hubbub of campus life. In the case of extra-long classes, a mid-session ringing of the mindfulness bell, with accompanying mindful breathing, gives students an opportunity to refresh their minds and their capacity to be open and listen deeply to what is transpiring.

Formal mindfulness meditation can be practiced as a sitting meditation, as described above, or as a walking meditation. Walking meditation involves combining mindful breathing and walking, with the steps synchronized 
with the body's breathing. Although there may be a destination for the walk, the emphasis is on walking for the sake of walking. Consequently, the idea is not to be in a hurry to get somewhere. Mindful walking can be slow one step for each in breath and one for each out breath - or fast, two or three steps for each in breath and each out breath. Short in-class mindfulness practices will be greatly enhanced in effectiveness if students engage in mindfulness meditation outside of class. Ideally, two 15-20 minute sittings, plus a mindfulness walking session, can be extremely valuable to the student.

Benefits of mindfulness meditation for the student include heightened awareness, feelings of awakening, capacity to focus and observe calmly, ability to acknowledge and process negative feelings and nurture positive feelings, a sense of unity and compassion, and establishing a foundation and preparation for contemplation and contemplative activities.

\section{Mindfulness Contemplation and Contemplative Activities}

Contemplation consists of focusing on a selected object using the mindfulness contemplation process. This object can be anything, e.g. a physical object, an idea, a reading, someone reciting or lecturing. What is important is the contemplative process itself. Below is a description of the basic steps of the contemplative process based on a combination of Buddhist and Confucian practices (Carroll, 2011).

- $\quad$ Rest the mind in the present moment using mindfulness meditation.

- Shift one's focus to contemplation.

- $\quad$ Actively consider the object by opening the mind to the object, appreciating and synchronizing oneself with the object while avoiding judgment.

- $\quad$ Permit insight to touch the heart.

- $\quad$ Conclude with a positively intended aspiration.

- Let go of the experience and move on, allowing the experience to naturally penetrate into the heart and mind.

This process is an extension of mindfulness awareness into observation and reflection on any object, including ideas and statements. It involves observation in the present moment, looking, listening and reflecting deeply, seeking to make spiritual insight immediate, personal and real. This active, personal and empathic involvement with the object enables personal direct discovery of the truth of the matter. This is the moment of insight touching the heart. The importance of the last step in the process, i.e., letting go, is in contrast to the impulse to hold onto the experience of the insight or to try to memorize what has been learned. The fruits of contemplation penetrate our consciousness and integrate naturally into awareness. This is very different from scholastic memorization. Because contemplative insight becomes part of who we are, it is far more long-lasting than memorized facts and theorems from normal academic study. It is an essential experience for achieving integrative learning.

Contemplative activities can involve reflecting on any object whether it is a poem or the definition of economics as determining the optimal allocation of scarce resources. The role of the instructor in contemplative studies is to facilitate contemplative activities. This is no easy task and requires providing a calm and supportive environment with the right amount of guidance and stimuli, while never controlling or manipulating the student. Ultimately, contemplation, and engagement in contemplative activities, must be an independent and voluntary activity for the student. It can never be forced or commanded. Examples of contemplative activities within and outside the classroom can include reading an assignment, pondering an economics principle, deeply listening to the instructor or a fellow student, reciting an economic law, listening to a statement about economic ethics, and reflecting on the meaning of demand or the consequences of a change in economic policy.

An important aspect of contemplative activities derived from mindfulness meditation is the capacity to engage in deep listening. This allows the listener to receive and comprehend a far greater amount of information from the speaker through verbal and other communication channels in a manner that supports deep understanding and empathy. 


\section{Integrating Mindfulness Practices into the Classroom}

Integrating mindfulness practices into student learning experiences should be voluntary and gradual. For that matter, practices should never be forced on the students or teacher. Based on the author's own teaching experience, a good first step in introducing mindfulness practices into the classroom is the introduction of mindfulness bell with two or three minutes of breathing meditation at the beginning and end of class. It is important that the instructor already be comfortable with this practice before introducing it in the classroom and that the process be introduced modestly as a voluntary practice that may improve focus and awareness in class. If there is interest, it is important to emphasize that this is a voluntary process. In addition, it is important not to identify this, or any other mindfulness practice, as a religious activity, which it is not.

\section{AREAS FOR ECONOMICS LEARNING ENCHANCEMENT}

\section{Grasping Abstract Economic Concepts}

Economics is a theory-intensive discipline and theory requires a great amount of abstract thinking. Instructors frequently observe that many students find it hard to deal with abstract thinking in economics. Yet, being able to ponder and grasp abstractions is an essential part of learning economics. Definitions of key economic variables, like demand or supply, are deceptively simple on the surface but conceal an immense complexity of issues. An abstraction in this context can be defined as a simplification which pulls out only the essence that you need to understand something (Morong, 2006a). Economic abstractions are necessary riddles that must be grasped to understand the laws and interrelationships of economic theory. Formulations, like Paul Krugman's "increased productivity, can reduce employment in one sector of the economy but increase it elsewhere while everyone gains" (Morong, 2006b), or "corn subsidies increase wheat prices" challenge the student to ponder deeply economic interrelationships implicit to the theory.

Indicators of student difficulty with abstract thinking include blank stares in response to an economic abstraction. Some students cannot understand the dynamics of supply and demand, although they can be trained to memorize each as a curve on a graph. In spite of this, they may easily slip back to confusing demand and quantity demanded or confuse a shift in demand with changes in quantity demanded on an existing demand curve. Good economics teachers use stories, analogies, concrete examples and a variety of other methods to encourage students to understand these basic concepts, knowing that if these abstract concepts are not successfully absorbed by the student, learning will only get more difficult as the course continues.

Students lacking a firm abstract conceptual footing in an introductory microeconomics or macroeconomics course are likely to fall behind and experience disappointing results. In this case, like many before them, they may stay far away from economic thought and inquiry for the rest of their lives, depriving themselves and society of their economic judgment. No doubt, an analogous prognosis can be rendered for accounting students that cannot conceptually break through the barrier of truly learning the language of the debit and credits. It is easy to say that some students need to pay more attention and be more focused on their work, but do we, as educators, know how this is actually achieved, much less, how we can contribute to, or facilitate, this process in students?

Providing the student with an opportunity to experience the process of mindfulness meditation can produce calmness and clarity in the student's mind and body, even if this is limited to a few minutes at the beginning and end of class. This continued process within the classroom, supported by students beginning to practice meditation on her/his own outside of class, can transform the student's personal experience of participating in the classroom and studying outside of class. Clearing the mind of distraction that may include negative expectations about self and the subject matter enables the student to open his/her mind and heart when listening to the instructor or reading study materials. Many students do not spend much time fully present in the moment and rarely experience the increased focus and openness that is created. In such a state of calm awareness, the student will find it much easier to grasp an abstract idea on first hearing or reading, or to contemplate the abstraction in a way that creates a personal insight into the concept. Through this process the student has an opportunity to truly use to full advantage what Cyril Morong characterized as a "simplification that pulls out only the essence you need to understand something" (Morong, 2006a). 


\section{Seeing Beyond Obvious Economic Consequences}

One of the objectives that economics teachers try to achieve is to get their students to see beyond the immediate effects of an economic policy. The French Economist Frederic Bastiat wrote over 150 years ago:

There is only one difference between a bad economist and a good one: the bad economist confines himself to the visible effect and the good economist takes into account both the effect that can be seen and those effects that must be foreseen (Bastiat, 1995).

The effects of a policy that come later and are not immediately obvious are called the secondary or the unintended consequences. For example, the immediate effect of minimum wage law is to raise the wages of those who continue to find employment, a secondary effect is that it reduces the quantity demanded of labor which in turn reduces employment opportunities. The capability to foresee the unintended consequences, the development of which is an important goal of an economics education, has been termed the "economic imagination" (ChamleeWright, 2011).

If economic imagination is a mode of thinking that can elude bad economists, it is no surprise that it is a difficult skill to teach beginning economics students. Seeing the unseen is not a capability that can be learned or taught through memorization or the usual forms of discourse within the classroom. Asking a potentially profound question does not guarantee a profound or original answer. As instructors, we try to guide and structure course activities to lead students in a desired direction. Often we use well baited questions to fish for powerful answers, but often the hook comes back empty. Clearly, students must be fully and personally engaged in the material in order to grasp the interconnectedness of economic theory, and the economy, well enough to recognize the "unforeseen" connections. Achieving such a level of personal involvement may sometimes require more than can be achieved with the best of cognitive educational resources.

Mindful cultivation of the student's economic imagination begins with the experience of mindfulness meditation, enabling the student to be fully in the present moment. This is the state of mindfulness. It can clear the mind of negative thoughts and distractions that present an obstacle to focus. At the same time, mindfulness is a state of openness of mind and heart that permits the freedom needed to cultivate the student's own economic imagination. Mindful meditation generates in the mind a strong personal experience of the unity and of the interconnectedness of all things in the universe, including all beings. The challenge is to continue to be in the present moment after mindfulness meditation by engaging in the contemplation of individual economic objects.

Seeing the unseen or the not obvious economic consequences of an event requires a high level of awareness and focus associated with contemplative activities. Noticing what is not visible, as well as what is visible, involves using mental processes addressed in Gestalt psychology theory which maintains that the brain is holistic, parallel, and analog, with self-organizing tendencies (Carlson, Miller, Heth, Donahoe, \& Martin, 2010). Contemplation allows the mind to perceive the interrelationships of markets as a direct experience in which it is possible to grasp the options open to economic agents and the consequences of actions affecting agents and markets. Mindfulness meditation and contemplation enables the student to look and listen deeply to the object. It is not limited to surface or superficial appearances. Such vision is driven by personal experience of the wholeness and interconnectedness of economic events.

\section{Finding One's Own Ethical Framework in Economic Analysis}

There is an increasing emphasis from both outside and within for economists to be conscious of the ethical framework that informs their analysis of economic outcomes. Jonathan Wright argues that the supposed 'positive' economic analysis taught to undergraduates is, in fact, highly value-laden (Wright, 2012). For instance, when economists say that free trade increases national welfare, they are making the implicit ethical claim that only outcomes matter and, specifically, those that satisfy certain particular individual preferences. People with a different ethical framework; for example, one that emphasizes process or rights rather than outcomes, might understandably disagree with the policy implications that flow from standard economic analysis. Being personally conscious of one's ethical framework would enable economists to identify the source of their disagreement with others. Being 
aware of one's own ethical reasoning and assumptions can enable economists to make policy recommendations that take into account the ethical framework of the society that they are studying.

Adolescents and young adult students are exposed to a variety of new circumstances, e.g. new surroundings, new relationships, new academic and cultural stimuli, and, for many, a new greater degree of freedom that they have previously known. The need to meet academic requirements and make social adjustments, combined with experiencing hormonal and psychological changes, can be overwhelming. Students cope in different ways. Many become manic and overactive, while others may become depressed and lethargic. Most manage to keep things together for outward appearances, striving to be accepted by their teachers and peer group. All are distracted and find little time or space for self-reflection. As instructors, we may share our own ethical concerns or discuss economic situations that we think will bring out the student's ethical involvement. We try to encourage discussion of ethical values relating to economic policy decisions. However, given their circumstances, it is difficult to expect that the students are clear in their own minds as to their personal ethical framework.

The mindfulness meditation process frees not only the mind, but the heart from the many distractions, worries, fears and biases that may otherwise dominate the student's thinking. Habitual thoughts, beliefs and judgments and many negative feelings, including ethical judgments, are constantly running on automatic pilot in the brain. Much of this thinking may have been passed on from parents, relationships, peer group, the media and a thousand other sources. Mindful breathing calms and temporarily frees the mind from these influences, enabling the student to experience what is true for him/her in the present moment. This openness continues to be cultivated in mindful contemplation. Through such introspective contemplation, a student can experience directly the framework of her/his own ethical values.

Ultimately, meditation tends to lead to a strong sense of compassion for oneself and others. In the eastern tradition, the ethical framework of mindfulness is compassion and loving kindness for all beings, all living things and all of nature. However, each individual must choose his/her own ethical path. Whatever ethical framework the student may arrive at through contemplative introspection, mindful experiences will help to develop a strong sense of empathy for the wants and needs of others and heightened sensitivity to the ethical consequences of actions, including changes in economic policy. Also, since the mindful student will look and listen deeply to differing arguments of others on economic utility and other ethical issues in economics, he/she will be more likely to appreciate the ethical values underlying each theory, as well as the economic consequences of actions based on these theories.

\section{THE MINDFUL ECONOMICS CLASSROOM}

In the mindful economics classroom, students and instructor are enabled to practice deep listening of one another. This principle of deep listening is also realized in the openness of the mind to new ideas and concepts that can be personally experienced through contemplative activities. The result of this experience is a profound sense of involvement with the subject matter of economics, as well as, with the thoughts and interests of all the classroom participants. Deep listening is in total contrast to multitasking, a popular idea among students and many busy adults. Psychology research studies have established that multitasking is not the mind exercising its capacity to attend to two different things simultaneously, but rather a process of rapidly switching back and forth from one activity to the other, while missing parts of each (Rubinstein, Meyer, \& Evans, 2001). In fact, psychiatrist Edward M. Hallowell characterizes multitasking as a "mythical activity" (Hallowell, 2007). In contrast, deep listening allows the student to be fully listening. Someone can be totally engaged in deep listening or totally engaged in texting on a cell phone, but cannot be doing both in the same moment.

Mindfulness meditation and contemplative activities are both based on the student's experience of being totally present in the present moment. In this state, the student is able to transcend habitual mental behaviors, prior beliefs and biases that might normally close off the mind from experiencing new ideas and values introduced in the classroom. Freed of mental baggage, each student may experience the calmness and focus that makes mindfulness contemplation so creative and productive. The energy of calmness and focus in each member of the class creates powerful group energy of calmness and focused awareness in the entire class. 
Although there are specific contemplative activities that can be developed specifically for the mindful economics classroom, basically what we are describing is any mindful classroom. The mindful classroom is supported by the foundation of mindfulness practices. For the instructor, this foundation complements and makes more effective the many useful cognitive teaching methods that are already at her/his disposal. As educators, we all probably have a picture of an ideal class in which every new avenue taken leads to student growth and understanding and where vacant stares are replaced by expressions of interest and insight. A mindful economics classroom, as suggested above, may not yet be fully realized, but it is a goal worth pursuing in our search for better teaching and learning.

\section{CONCLUSION}

Although empirical research on mindfulness mediation practices and learning are already being conducted by neurological specialists, there is no empirical research on the results of mindfulness meditation and contemplative practices in the economics classroom or, for that matter, in higher education, generally. Such research will require careful design and student assessment criteria. A prerequisite for any such research will be to gain a fuller understanding of how mindfulness practices are actually being used in the diverse mindfulness and contemplative study programs already in existence or being developed. This will require a review of many programs and curricula at various institutions.

The current study shares general applications of eastern mindfulness meditation and contemplative practices as a new dimension in teaching and learning that can contribute to economics and business-related academic programs. The benefits of these practices can and, are being extended to a whole range of academic disciplines, including the humanities and the arts, social and natural sciences, law, and medicine. In each of these areas, we can anticipate an accumulating literature describing the specific classroom methods and materials that have been used successfully to facilitate the integration of mindfulness and contemplative practices into instruction and student learning. This sharing of information is only beginning. Many important benefits of these practices await our discovery. ${ }^{1}$

\section{AUTHOR INFORMATION}

David Borker has a Ph.D. from Yale with a Master of Accounting/MBA from Ohio State University and an A.B. from Cornell. In addition to his academic and international/multicultural corporate and consulting experience, Dr. Borker has been deeply involved for several decades in developing and delivering innovative instruction at the graduate and undergraduate level in business management, accounting and economics. He teaches accounting, economics and management at Manhattanville College and is a licensed CPA. E-mail: David.Borker@mville.edu

\section{REFERENCES}

1. $\quad$ Alexandrin, G. (1981). Toward a Buddhist Economics. Strategy \& Leadership, 9(5), 28-32.

2. Ash, C. (2008). Happiness and Economics: A Buddhist Perspective. Centre for Institutional Performance Working Paper Series(CIP Working Paper No. 2008-059), pp. 1-20.

3. Awbrey S., D. D. (2006). Integrative Learning and Action (Studies in Education and Spirituality). New York: Peter Lang.

4. $\quad$ Barbezat, D. (2013). "Wanting: Teaching Economics with Contemplative Methods." (Webinar). Center for Contemplative Mind. Retrieved from http://www.contemplativemind.org/archives/1517

5. Barbezat, D., \& Pingree, A. (2012). Contemplative Pedagogy: The Special Role of Teaching and Learning Centers Volume 31. In J. E. Groccia, \& L. Cruz, To Improve the Academy, Resources for Faculty, Instructional, and Organizational Development (pp. 177-195). Jossey-Bass, A Wiley Imprint.

\footnotetext{
${ }^{1}$ The current paper is a highly revised version of an oral presentation given at the Eastern Economic Association Annual 2013 Conference in New York City. I am grateful to my colleague, Dr. Nimish Adhia, Manhattanville College, for contributing insights into teaching economics in the classroom. His input was instrumental in the development of my thinking on this topic.
} 
6. Bastiat, F. (1995). What is Seen and What is not Seen. In Selected Essays on Political Economy (p. 1). Irvington, New York: Foundation for Economic Education.

7. Borden, M. E., \& Shekhawat, P. S. (2010). Buddhist Practice and Principles and their Place in Organizations. In Spirituality in Business Part 2. Springer.

8. Borker, D. R. (2013). Mindfulness Practices For Accounting And Business Education: A New Perspective. American Journal Of Business Education, 6(1), 41-55.

9. Bush, M. (2011). Mindfulness in Higher Education. Contemporary Buddhism, 12(1), 183-197.

10. Carlson, N. R., Miller, H., Heth, C. D., Donahoe, J. W., \& Martin, G. N. (2010). Psychology the Science of Behavior, 7th ed. Allyn \& Bacon Pearson Education, Inc.

11. Carroll, M. (2011). The Mindful Leader. Boston \& London: Trumpeter.

12. Chamlee-Wright, E. (2011). Cultivating Economic Imagination with Atlas Shrugged. Journal of Economics and Finance Education, 10(2), 197-204.

13. Chang, O. H., Davis, S. W., \& Kaufmann, K. D. (2011). Accounting Ethics Education: A Comparison with Buddhist Ethics Framework. Journal of Religion and Business Ethics, 3(1).

14. Davidson, R. J., Dunne, J., Eccles, J. S., Engle, A., Greenberg, M., Jennings, P., . . Vago, D. (2012). Contemplative Practices and Mental Training: Prospects for American Education. Child Development Perspectives, 6(2), 146-158.

15. Dollman, E., \& Bond, D. (2011). Mindful leadership: Exploring the Value of Meditation Practice. The Astridge Journal, 1-9.

16. Green, J. J., Stone, C. C., DeVon, \& Zegeye, A. (2013). Will They Ever Learn Economic Principles?: Are University Economics Faculty and Students Really That ObTUCE? Oral Presentation at Eastern Economic Association Meetings May 2013.

17. Hallowell, E. M. (2007). Crazy Busy: Overstretched, Overbooked, and About to Snap! Ballantine Books.

18. Hanh, T. N. (2012a). The Awakening oif the Heart: Essential Buddhist Sutras and Commentaries. Berkeley, CA: Parallax Press.

19. Hanh, T. N. (2012b). Art of Mindful Living. Retrieved from Plum Village: http://www.plumvillage.org/mindfulness-practice.html

20. Kabat-Zinn, J. (1982). An Outpatient Program in Behavior Medicine for Chronic Pain Patients Based on the Practice of Mindfulness Meditiation: Theoretical Considerations and Preliminary Results. General Hospital Psychiatry, 4(1), 33-47.

21. Langer, E. J., \& Moldoveanu, M. (2000). The Construct of Mindfulness. Journal of Social Issues, 56(1), 19.

22. Langer, E. J., Blank, A., \& Chanowitz, B. (1978). The Mindlessness of Ostensibly Thoughtful Action: The Role of "Placebic" Information in Interpersonal Interaction. Journal of Personality and Social Psychology, 36(6), 635-642.

23. Mahani, S. (2012). Promoting Mindfulness Through Contemplative Education. Journal of International Education Research, 8(3), 215-222.

24. Morong, C. (2006a, October 30). Retrieved from Cybermetrics: The sabermetric blog of Cyril "Cy" Morong, professor of Economics at San Antonio College: http://cybermetric.blogspot.com/

25. Morong, C. (2006b, October 29). Retrieved from The Dangerous Economist: http://thedangerouseconomist.blogspot.com/search?updated-min=2006-01-01T00:00:00-08:00\&updated$\underline{\max =2007-01-01 T 00: 00: 00-08: 00 \& \max -\text { results=30 }}$

26. Newmark, R., Krahnke, K., \& Seaton, L. (2012). Incorporating Mindfulness Meditation in the Classroom. 14th AISE Copnference Presentation. Retrieved from http://www.aiseducators.com/submissions/paper 615.pdf

27. Palmer, P. J. (2010). The heart of higher education: A call to renewal. San Francisco, CA: Jossey-Bass.

28. Ritchhart, R., \& Perkins, D. N. (2000). Life in the Mindful Classroom:Nuturing the Disposition. Journal of Social Issues, 56(1), 27-47.

29. Rubinstein, J., Meyer, D., \& Evans, J. (2001). Executive Control of Cognitive Processes in Task Switching. Journal of Experimental Human Perceptual Performance, 27(4), 763-797.

30. Rudy, N., \& Schweitzer, M. (2011). In the moment: The Effect of Mindfulness on Ethical Decision Making. Journal of Business Ethics, 1-15. doi:DOI: 10.1007/s10551-011-0796-y

31. Sen, A. (2013). How to judge Globalism. In Laws and Societies in Global Contexts (pp. 336-421). New York: Cambridge University Press. 
32. Smilovitz, R. (1996). If Not Now When? Education Not Schooling. Morris Publishing.

33. The Center for Contemplative Mind in Society. (2013). Contemplative Studies. Retrieved from The Center for Contemplative Mind in Society: http://www.contemplativemind.org/archives/tag/contemplative-studies

34. Williams, J. M., \& Kabat-Zinn, J. (2011). Mindfulness: Diverse Perspectives on its Meaning, Origins, and Multiple Applications at the Intesection of Science and Dharma. Contemporary Buddhism, 12(1), 1-18. doi:DOI: 10.1080/14639947.2011.564811

35. Wright, J. (2012). Ethics in Economics: A Critical-Thinking Approach. In G. M. McGoldrick (Ed.), International Handbook for Teaching Economics (pp. 197-204).

36. Zonjonc, A. (2006). Love and Knowledge: Recovering the Heart of Learning Through Contemplation. Teachers College Record, 108(9), 1742-1759. 